\title{
Fat embolism syndrome and elective knee arthroplasty
}

\author{
[Embolie graisseuse et arthroplastie du genou non urgente]
}

Kathryn Jenkins FRCA, ${ }^{*}$ Frances Chung FRCPC, ${ }^{*}$ Richard Wennberg FRCPC, $†$ Edward E. Etchells FRCPC, $\dagger$ Rod Davey FRCsC $\ddagger$

Purpose: To report a case of fat embolism syndrome (FES) following elective left knee arthroplasty and review the diagnosis, investigation, prevention and perioperative management of this condition. Clinical features: A 76-yr-old lady presented for left total knee arthroplasty under general anesthesia. After an uneventful anesthetic and initial recovery, she developed respiratory and neurological complications six hours postoperatively necessitating supportive care in the intensive care unit. Following extensive investigation, a clinical diagnosis of FES was made $48 \mathrm{hr}$ postoperatively supported by the development of diffuse encephalopathy, thrombocytopenia, hypoxemia, chest petechiae and chest $x$-ray changes. A magnetic resonance imaging scan five days postoperatively confirmed this diagnosis. Her postoperative course showed gradual improvement consistent with a slowly resolving encephalopathy.

Previous published cases of FES associated with knee arthroplasty present either with intraoperative cardiorespiratory collapse or, as with this patient, in the postoperative period with respiratory, cardiovascular and/or cerebral dysfunction.

Conclusions: The clinical diagnosis of FES is essentially one of exclusion, supported by laboratory and radiological investigations. Preoperative identification of at-risk patients, use of appropriate invasive perioperative monitoring and modified surgical techniques may minimize the development of the syndrome. Treatment is supportive.

Objectif : Décrire un cas d'embolie graisseuse (EG) survenue après une arthroplastie du genou non urgente et réexaminer le diagnostic, la recherche, la prévention et le traitement périopératoire entourant cette situation.

Éléments cliniques : Une femme de 76 ans s'est présentée pour une arthroplastie totale du genou gauche sous anesthésie générale. La récupération, d'abord sans incident, s'est compliquée de troubles respiratoires et neurologiques six heures après l'intervention, ce qui a nécessité un traitement de soutien à l'unité des soins intensifs. À la suite d'une investigation poussée, un diagnostic d'EG a été fait, $48 \mathrm{~h}$ après l'opération, confirmé par le développement d'encéphalopathie diffuse, de thrombocytopénie, d'hypoxémie, de pétéchies thoraciques et de modifications radiographiques pulmonaires. Un examen d'imagerie par résonance magnétique a confirmé le diagnostic cinq jours après l'opération. L'état de la patiente s'est graduellement amélioré en faveur d'une lente résolution de l'encéphalopathie.

Dans les cas déjà publiés d'EG associée à l'arthroplastie du genou, on retrouve soit un collapsus cardiorespiratoire peropératoire, soit un dérèglement postopératoire respiratoire, cardiovasculaire et/ou cérébral comme dans le cas présent.

Conclusion : Le diagnostic clinique d'EG est essentiellement un diagnostic d'exclusion, corroboré par les examens de laboratoire et de radiographie. L'identification préopératoire des patients à risque, l'usage d'un monitorage périopératoire effractif approprié et de techniques chirurgicales modifiées peuvent minimiser le développement de ce syndrome. Le traitement consiste en une thérapie de soutien.

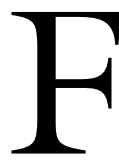

AT embolism syndrome (FES) has been recognized since the late 1800's and extensively described following traumatic, surgical and atraumatic conditions. We present a case of FES following elective left knee arthroplasty. Previous published case reports of FES associated with elective knee arthroplasty are summarized, revealing common patterns of presentation. Recommendations for perioperative management are suggested to minimize the risk of this syndrome during knee arthroplasty.

\section{Case report}

A 76-yr-old female, weighing $66 \mathrm{~kg}$, with osteoarthritis of her left knee presented for left total knee arthroplasty in September 2000. Her past medical history included

From the Departments of Anesthesia, ${ }^{*}$ Medicine, $\dagger$ and Orthopedic Surgery, $\ddagger$ University of Toronto, Toronto Western Hospital, Toronto, Ontario, Canada.

Address correspondence to: Dr. Frances Chung, Department of Anesthesia, Toronto Western Hospital, 399 Bathurst Street, Toronto,

Ontario M5T 2S8, Canada. Phone: 416-603-5118; Fax: 416-603-6494; E-mail: frances.chung@uhn.on.ca

Accepted for publication July 18, 2001.

Revision accepted October 22, 2001. 
osteotomy of right hip, right knee arthroplasty, cholecystectomy, hysterectomy, appendectomy, bowel resection for diverticulitis, posterior fossa craniotomy for cerebello-pontine angle tumour, lower lumbar disc pathology and a hiatus hernia with reflux. She had a five-year history of stable angina. Her medication included atenolol $100 \mathrm{mg}$ once daily and nitroglycerin spray as required. Preoperative echocardiography revealed mild global left ventricular dysfunction and infero-basal hypokinesis consistent with regional ischemia. A 1996 thallium scan was normal, and her electrocardiogram (ECG) revealed longstanding left bundle branch block (LBBB). Preoperative vital signs and blood tests were normal. Preoperative venous thrombo-prophylaxis with oral coumadin had been commenced.

The patient had a left total knee arthroplasty, using a thigh tourniquet, under general anesthesia. A cemented total condylar system was inserted, using femoral and tibial intramedullary alignment rods. With standard monitoring, a rapid sequence induction was carried out with fentanyl $250 \mu \mathrm{g}$, propofol $120 \mathrm{mg}$ and suxamethonium $150 \mathrm{mg}$. Anesthesia was maintained with desflurane (end-tidal concentrations 2-3\%) in nitrous oxide $(70 \%)$ and oxygen. The patient was paralyzed with rocuronium, and morphine $8 \mathrm{mg}$ was given intraoperatively for analgesia. Estimated intraoperative blood loss was $100 \mathrm{~mL}$ and the patient received 1600 $\mathrm{mL}$ of $0.9 \%$ saline intravenously. Vital signs were stable throughout the intraoperative course $(2.5 \mathrm{hr})$. On recovery from anesthesia, the patient was awake, alert and hemodynamically stable. She required supplemental oxygen via a Venturi mask $\left(\mathrm{FIO}_{2} 0.5\right)$ to maintain oxygen saturations of $97 \%$ following a transient drop in saturations to $90 \%$ in the postanesthesia care unit on 4 $\mathrm{L} \cdot \mathrm{min}^{-1}$ oxygen via nasal prongs. Morphine patientcontrolled analgesia was provided. She achieved a maximal Aldrete postoperative recovery score of 10 prior to discharge to the ward.

Six hours postoperatively, she was noted to be increasingly drowsy, opening eyes to voice, withdrawing to pain but no verbal response. She was hemodynamically stable with a respiratory rate of $16 \cdot \mathrm{min}^{-1}$, and saturations of $97 \%$ on oxygen $\mathrm{FIO}_{2}$ 0.5. Arterial blood gases $(\mathrm{ABG})$ revealed $\mathrm{pH} 7.47, \mathrm{pCO}_{2} 42 \mathrm{mmHg}, \mathrm{pO}_{2}$ $92 \mathrm{mmHg}$, base excess -0.3 , saturations $97 \%$ on $50 \%$ inspired oxygen; Hb $127 \mathrm{~g} \cdot \mathrm{L}^{-1}$, WBC $16.8 \times 10^{9} \cdot \mathrm{L}^{-1}$, platelets $163 \times 10^{9} \cdot \mathrm{L}^{-1} ;$ glucose $7.5 \mathrm{mmoL} \cdot \mathrm{L}^{-1}$; Troponin $\mathrm{C} 0.6 \mu \mathrm{g} \cdot \mathrm{L}^{-1}$. There was no detectable metabolic derangement. Her ECG was unchanged (LBBB). The chest $x$-ray showed bilateral diffuse infiltrates consistent with pulmonary edema. Furosemide $40 \mathrm{mg}$ iv was administered which resulted in urinary diuresis but no improvement in ABG.
With further deterioration in her neurological status $24 \mathrm{hr}$ postoperatively, she was transferred to the intensive care unit. Neurological examination revealed the patient to be stuporous with no focal signs and bilateral extensor plantar responses. No retinal fat or petechiae were seen. A cerebral computed tomogram (CT) was normal. Repeat ABG on $50 \%$ oxygen had deteriorated: $\mathrm{pH}$ 7.46, $\mathrm{pO}_{2} 80 \mathrm{mmHg}, \mathrm{pCO}_{2} 36$ $\mathrm{mmHg}$, base excess 2.3 , saturations $95 \%$. There was no evidence of deep venous thromboses clinically or on venous ultrasounds. A lumbar puncture revealed no abnormality of cerebrospinal fluid. No other sources of sepsis were identified.

At $48 \mathrm{hr}$ postoperatively, fat embolism was suspected, supported by the development of petechiae on the upper trunk and thrombocytopenia (platelets $98 \times$ $\left.10^{9} \cdot \mathrm{L}^{-1}\right)$. Magnetic resonance imaging (MRI) was carried out five days postoperatively which revealed multiple small bilateral predominantly white matter changes preferentially located in the fronto-parietal "watershed" area between the major hemispheric vascular territories (Figure, top). The abnormalities appeared as hyperintense lesions on T2-weighted and fluid-attenuated inversion recovery (FLAIR) sequences: Tl-weighted sequences were normal. A repeat CT was unchanged. Electroencephalography showed an abnormal diffuse theta recording with no focal abnormalities. A repeat echocardiogram five days postoperatively detected $8 \mathrm{~mm}$ left to right shunt flow across an interatrial septum consistent with an atrial septal defect or patent foramen ovale.

Her subsequent postoperative course showed gradual improvement of neurological status consistent with a slowly resolving encephalopathy. A repeat MRI one month later showed resolution of the fronto-parietal lesions (Figure, bottom).

\section{Discussion}

Fat embolism occurs in almost all lower extremity trauma and intramedullary surgery. FES, however, is a severe multisystem manifestation of embolization that occurs much less commonly. The incidence of FES in retrospective reviews is less than $1 \% .^{1,2}$ However, there is a greater incidence reported in prospective studies of $11-29 \% .^{3-6}$ Overall mortality varies between $7-20 \%, 1,2$ and long-term morbidity is usually due to neurological dysfunction. ${ }^{7}$

The commonest surgical procedures predisposing to FES are intramedullary nailing of long bones, hip arthroplasty and knee arthroplasty. ${ }^{7}$ Over the last 30 years, FES associated with knee arthroplasty has been described in at least 16 case reports. ${ }^{8-21}$ Of these, seven proved fatal and one had poor long-term neu- 

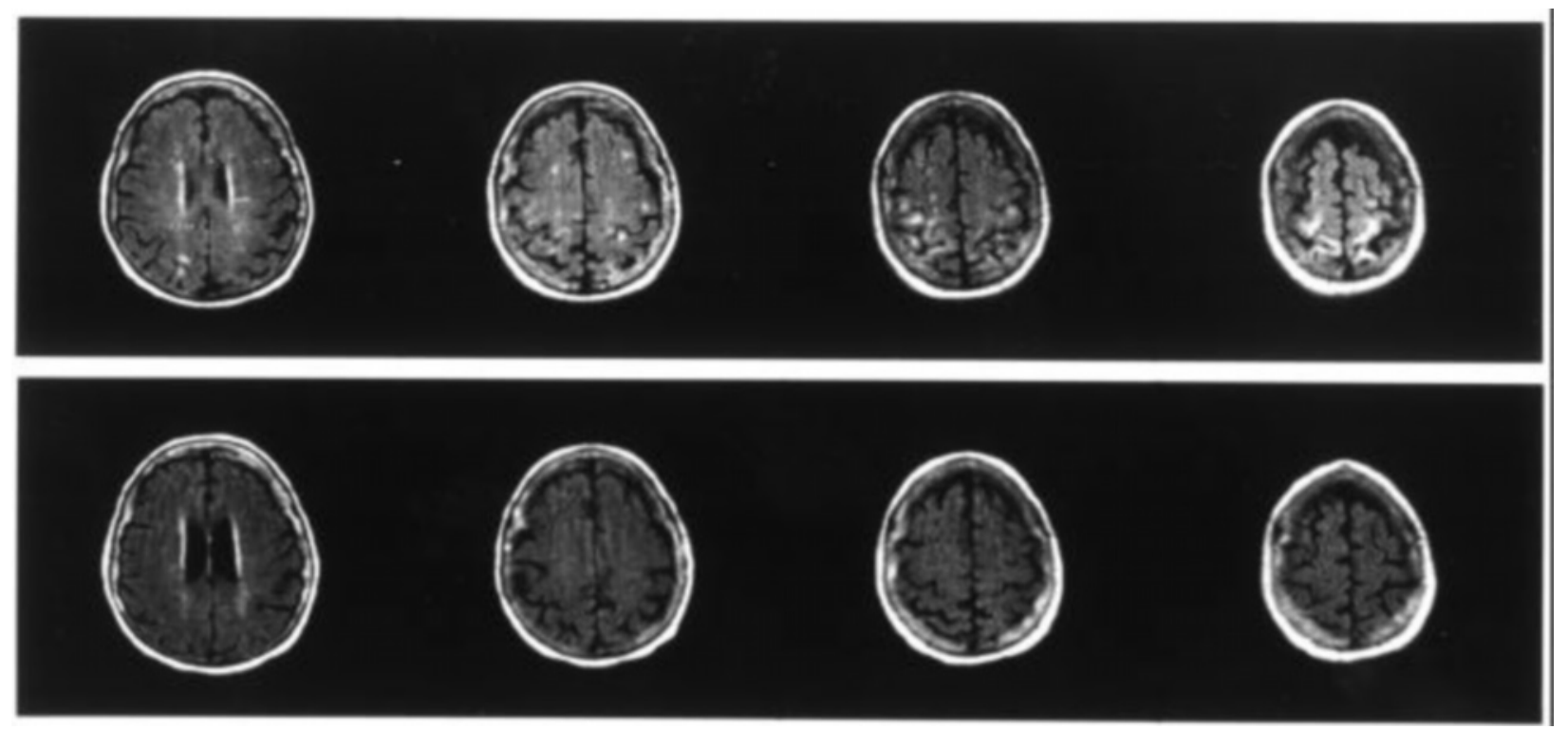

FIGURE Top; Brain magnetic resonance imaging (MRI) five days postoperatively shows multiple small hyperintense lesions on fluidattenuated inversion recovery sequences preferentially located in "watershed" area between major hemispheric vascular territories. Bottom; Repeat MRI one month later shows resolution of abnormalities.

rological outcome. The remaining $50 \%$ recovered completely.

Clinical presentation in these patients can be divided into two distinct groups. Eight patients presented with intraoperative cardiorespiratory collapse follow ing femoral reaming, ${ }^{1}$ insertion of intramedullary alignment guide ${ }^{1}$ or cemented prosthesis, ${ }^{2}$ or after tourniquet release. ${ }^{4}$ Hypotension was recorded in seven to eight of these cases, with three progressing to electromechanical dissociation. Hypoxia was noted in five patients. Two patients in this group died.

Six patients presented in the postoperative period, varying from immediately postoperatively to four hours later. Only one patient had been unstable intraoperatively, with transient hypotension following tourniquet release. Postoperatively, all patients developed neurological signs, specifically disorientation or unconsciousness, and hypoxemia. In two patients this was associated with hypotension, and another developed signs of cardiac ischemia (segment depression on ECG). Three patients in this group died, and one had poor neurological recovery.

The diagnosis of FES is clinical, usually one of exclusion. Differential diagnoses of cardiorespiratory and neurological dysfunction include myocardial infarction, cardiogenic shock, infection or sepsis, pulmonary embolism, cerebrovascular accident or metabolic disturbance. In this patient with known ischemic heart disease, relative fluid overload from perioperative $i v$ administration must also be considered.

In trauma patients, respiratory signs are seen in $75 \%$, which may progress to respiratory failure in $10 \% .7,22$ Neurological changes, seen in up to $86 \%$ of patients, may present as diffuse encephalopathy and/or with focal abnormalities. ${ }^{2}{ }^{3}$ Petechiae, which represent dermal fat embolization, are seen in 50-60\% of cases usually after $24-48 \mathrm{hr} .^{2}$ They are usually distributed to the upper body-chest, neck and conjunctivae. Resolution occurs within seven days. Other non-specific symptoms, such as tachycardia, fever, retinal changes, jaundice and lipuria may also be seen. ${ }^{7,22}$

There are no universal criteria used for diagnosis. Those published by Gurd et al. in $1970^{2} 2$ divided the symptoms into major and minor features for diagnosis (Table I). These criteria have been criticized for not specifically assessing oxygenation with $A B G$ that may be a useful early indicator of FES. ${ }^{5}$ Schonfeld's scoring system incorporated this ${ }^{6}$ (Table II) and Lindeque proposed respiratory parameters as alternative criteria for diagnosis of FES in trauma patients (Table III). Our patient had clinical evidence of FES by both Gurd's and Schonfeld's criteria.

No investigation is $100 \%$ specific for the syndrome. Laboratory tests should include ABG, complete blood count to identify anemia or thrombocytopenia, and a coagulation profile to reveal bone marrow thrombo- 
TABLE I Gurd's criteria for diagnosis of FES 22

\begin{tabular}{ll}
\hline $\begin{array}{l}\text { Major criteria } \\
\text { (one necessary for diagnosis) }\end{array}$ & $\begin{array}{l}\text { Petechial rash } \\
\text { Respiratory insufficiency } \\
\text { Cerebral involvement }\end{array}$ \\
$\begin{array}{l}\text { Minor criteria } \\
\text { (four necessary for diagnosis) }\end{array}$ & $\begin{array}{l}\text { Tachycardia }>120 \text { beats } \cdot \mathrm{min}^{-1} \\
\text { Fetinal signs }- \text { fat or petechiae } \\
\text { Jaundice } \\
\text { Renal signs }- \text { anuria or oliguria }\end{array}$ \\
Laboratory findings & $\begin{array}{l}\text { Thrombocytopenia } \\
\text { (one necessary for diagnosis) }\end{array}$ \\
rate & $\begin{array}{l}\text { High erythrocyte sedimentation } \\
\text { Fat macroglobulinemia }\end{array}$ \\
\hline
\end{tabular}

FES=fat embolism syndrome.

TABLE II Schonfeld's criteria for diagnosis of FES ${ }^{6}$

Cumulative score $>5$ required for diagnosis

Petechiae [5]

Chest $x$-ray changes [4]

Hypoxemia [3]

Fever [1]

Tachycardia [1]

Tachypnea [1]

Confusion [1]

FES=fat embolism syndrome.

TABLE III Lindeque's criteria for diagnosis of $\mathrm{FES}^{5}$

1 Sustained $\mathrm{pO}_{2}<8 \mathrm{kPa}$

2 Sustained $\mathrm{pCO}_{2}$ of $>7.3 \mathrm{kPa}$ or a $\mathrm{pH}<7.3$

3 Sustained respiratory rate $>35 \cdot \mathrm{min}^{-1}$ despite sedation

4 Increased work of breathing: dyspnea, accessory muscle use, tachycardia and anxiety.

FES=fat embolism syndrome.

plastin- or complement-mediated coagulopathies. ${ }^{23}$ Any other treatable causes of neurological dysfunction, e.g., toxic, metabolic or infectious, must be excluded. ${ }^{24}$ Urinalysis may reveal fat globules but this is non-specific. The ECG may be normal, reflect right heart strain or may reveal ischemia. ${ }^{7}$ The chest radiograph is non-specific, with diffuse fluffy bilateral infiltrates and opacities consistent with increased capillary permeability and edema. ${ }^{7}$ MRI has been shown to be more sensitive than CT in the identification of cerebral FES, with the abnormalities typically appearing as hyperintense lesions on T2-weighted, proton density and FLAIR sequences, characteristically located along the boundary zones of the major vascular ter- ritories, ${ }^{25}$ as was the case in our patient. This "watershed" distribution of the MRI abnormalities presumably represents a tendency for the embolic particles to lodge in the small terminal branches of the major hemispheric vessels.

Identification of at risk patients preoperatively is important. Medically, those with pre-existing cardiac or respiratory disease have decreased physiological reserve, and are at greater risk of cardiorespiratory collapse following an embolic load. Patients with metastatic disease, myeloblastic disorders, rheumatoid arthritis, collagen vascular disease or osteopenia are at risk due to enlargement and increased liquid marrow content of the medullary canals. ${ }^{19}$ The risk may be increased in bilateral surgical procedures, presumably due to increased embolic load. A patent foramen ovale, present in up to $34 \%$ of people, ${ }^{26}$ provides a means of paradoxical fat embolization in the event of pulmonary hypertension and increased right atrial pressure.

Intraoperatively, in addition to standard monitoring in high-risk patients or procedures, use of an arterial line for continuous hemodynamic and blood gas monitoring is recommended. ${ }^{2}$ Intraoperative transesophageal echocardiography may detect fat embolization and monitor intraoperative volume status and cardiac function. ${ }^{2}$ Pulmonary artery pressure monitoring has also been recommended, both as a diagnostic and prognostic tool, in bilateral procedures. ${ }^{2}$ Although more invasive monitoring improves detection of embolization and its sequelae, there is no evidence to suggest these interventions improve outcome in FES.

Close postoperative monitoring should identify early signs of respiratory deterioration, using routine pulse oximetry, regular blood gas analysis and supplemental oxygen. ${ }^{2} 1$

Modification of surgical technique may lessen the risk. Increased intramedullary pressure has been implicated as the source of fat emboli due to fat intravasation from the bone marrow cavity. ${ }^{7}$ The shift towards the use of total condylar components from long-stemmed prostheses obviates the need for extensive intramedullary manipulation. However, intramedullary alignment guides have also been implicated. ${ }^{18}$ Venting of the femoral shaft and lavage of the medullary canal minimizes increases in intramedullary pressure and the amount of fatty bone marrow present. ${ }^{21}$ Methylmethacrylate cement insertion results in pressurization of the intramedullary fat and direct vasodilatation leading to transient hypotension. ${ }^{27}$ The presence of a tourniquet does not prevent embolization and FES but may modulate the time course of events and limits the vasodilatory consequences of the cement insertion. ${ }^{2}{ }^{1}$ 
To prevent hypoxemia intraoperatively, $100 \%$ oxygen administration during cementing and prosthesis insertion in patients at risk has been recommended anecdotally although there are no prospective studies confirming this. ${ }^{21}$ Fluid therapy to prevent hypovolemia is also important, as canine studies have shown that acute hemodynamic changes during prosthesis insertion and fat embolism may increase in hypovolemic states. ${ }^{27}$ Recent reports of intraoperative cardiac instability due to fat embolization have recommended maintenance of perfusion pressure with vasoconstrictors to preserve right heart perfusion and function. ${ }^{2} 3$

Treatment is essentially supportive, consisting of cardiovascular and respiratory resuscitation and stabilization. No specific drug therapy for FES is currently recommended. Small prospective randomized controlled studies of steroid prophylaxis in patients with long bone fractures have indicated both a decrease in development of FES and a decreased incidence of hypoxemia in steroid treated groups compared to controls. However, dose regimens were not standardized, varying from $1.5 \mathrm{mg} \cdot \mathrm{kg}^{-1}$ methylprednisolone 8 hourly to $30 \mathrm{mg} \cdot \mathrm{kg}^{-1} 4$ hourly. ${ }^{4}{ }^{5}$ In a canine model of cemented arthroplasties, Byrick et al. demonstrated no attenuation of hemodynamic or prostanoid response in acute lung injury following treatment with methylprednisolone $30 \mathrm{mg} \cdot \mathrm{kg}^{-1}$ iv $20 \mathrm{~min}$ prior to reaming. ${ }^{2} 8$ Other drugs, such as heparin, iv alcohol, dextrans and hypertonic dextrose, have not proved to be of any benefit and may be detrimental. ${ }^{21}$

In summary FES is a significant cause of mortality and morbidity not only in trauma patients but increasingly recognized in association with elective orthopedic surgery. Two main presentations are seen in knee arthroplasties: intraoperative cardiorespiratory collapse, or postoperative respiratory and cerebral dysfunction. A high index of suspicion is required for early clinical diagnosis in at-risk patients.

\section{References}

1 Bulger EM, Smith DG, Maier RV, Jurkovich GJ. Fat embolism syndrome. A 10-year review. Arch Surg 1997; 132: 435-9.

2 Robert JH, Hoffmeyer P, Broquet P-E, Cerutti P, Vasey $H$. Fat embolism syndrome. Orthop Rev 1993; 22: 567-71.

3 Fabian TC, Hoots AV, Stanford DS, Patterson CR, Mangiante EC. Fat embolism syndrome: prospective evaluation in 92 fracture patients. Crit Care Med 1990; 18: 42-6.

4 Kallenbach J, Lewis M, Zaltzman M, Feldman C, Orford A, Zwi S. 'Low-dose' corticosteroid prophylaxis against fat embolism. J Trauma 1987; 27: 1173-6.
5 Lindeque BGP, Schoeman HS, Dommisse GF, Boeyens $M C$, Vlok $A L$. Fat embolism and the fat embolism syndrome. A double-blind therapeutic study. J Bone Joint Surg Br 1987; 69: 128-31.

6 Schonfeld SA, Ploysongsang $\Upsilon$, DiLisio R, et al. Fat embolism prophylaxis with corticosteroids. A prospective study in high-risk patients. Ann Intern Med 1983; 99: 438-43.

7 Johnson MJ, Lucas GL. Fat embolism syndrome. Orthopedics 1996; 19: 41-50.

8 Weiss SJ, Cheung AT, Stecker MM, Garino JP, Hughes JE, Murphy FL Jr. Fatal paradoxical cerebral embolization during bilateral knee arthroplasty. Anesthesiology 1996; 84: 721-3.

9 Hume Adams J, Graham DI, Mills E, Sprunt TG. Fat embolism and cerebral infarction after use of methylmethacrylate cement. Brit Med J 1972; 3: 740-1.

10 Letournel E, LaGrange J. Total knee replacement with the "LL" type prosthesis. Clin Orthop 1973; 94 : 249-56.

11 Mallory TH, Kolodzik S. Fat embolization after total knee replacement (Letter). JAMA 1976; 236: 1451.

12 Browne $\mathrm{CH}$. A case of fat embolism following Shiers arthroplasty. Postgrad Med J 1976; 52: 247-9.

13 Bisla RS, Inglis AE, Lewis RJ. Fat embolism following bilateral total knee replacement with the Guepar prosthesis. A case report. Clin Orthop 1976; 115: 195-8.

14 Lachiewicz PF, Ranawat CS. Fat embolism syndrome following bilateral total knee replacement with total condylar prosthesis: report of two cases. Clin Orthop 1981; 160: 106-8.

15 Zimmerman RL, Kroner III LF, Blomberg DJ, Nollet DJ. Fatal fat embolism following total knee arthroplasty. Minn Med 1983; 66: 213-6.

16 Orsini EC, Richards RR, Mullen JMB. Fatal fat embolism during cemented total knee arthroplasty: a case report. Can J Surg 1986; 29: 385-6.

17 Byrick RJ, Forbes D, Waddell JP. A monitored cardiovascular collapse during cemented total knee replacement. Anesthesiology 1986; 65: 213-6.

18 Caillouette JT, Anzel SH. Fat embolism syndrome following the intramedullary alignment guide in total knee arthroplasty. Clin Orthop 1990; 251: 198-9.

19 Monto RR, Garcia J, Callaghan JJ. Fatal fat embolism following total condylar knee arthroplasty. J Arthroplasty 1990; 5: 291-9.

20 Hall TM, Callaghan JJ. Fat embolism precipitated by reaming of the femoral canal during revision of a total knee replacement. A case report. J Bone Joint Surg Am 1994; 76: 899-903.

21 Enneking FK. Cardiac arrest during total knee replacement using a long-stem prosthesis. J Clin Anesthesia 1995; 7: 253-63. 
22 Gurd AR, Wilson RI. The fat embolism syndrome. J Bone Joint Surg Br 1974; 56 B: 408-16.

23 Byrick RJ. Fat embolism and postoperative coagulopathy (Editorial). Can J Anesth 2001; 48: 618-21.

24 Jacobsen DM, Terrance CF, Reinmuth OM. The neurologic manifestations of fat embolism. Neurology 1986; 36: 847-51.

25 Stoeger A, Daniaux M, Felber S, Stockhammer G, Aichner F, zur Nedden D. MRI findings in cerebral fat embolism. Eur Radiol 1998; 8: 1590-3.

26 Hagen PT, Scholz DG, Edwards WD. Incidence and size of patent foramen ovale during the first ten decades of life: an autopsy study of 965 normal hearts. Mayo Clin Proc 1984; 59: 17-20.

27 Berman AT, Price HL, Habn JF. The cardiovascular effects of methylmethacrylate in dogs. Clin Orthop 1974; 100: 265-9.

28 Byrick RJ, Mullen JB, Wong PY, Kay JC, Wiggleworth $D$, Doran $R J$. Prostanoid production and pulmonary hypertension after fat embolism are not modified by methylprednisolone. Can J Anaesth 1991; 38: 660-70.

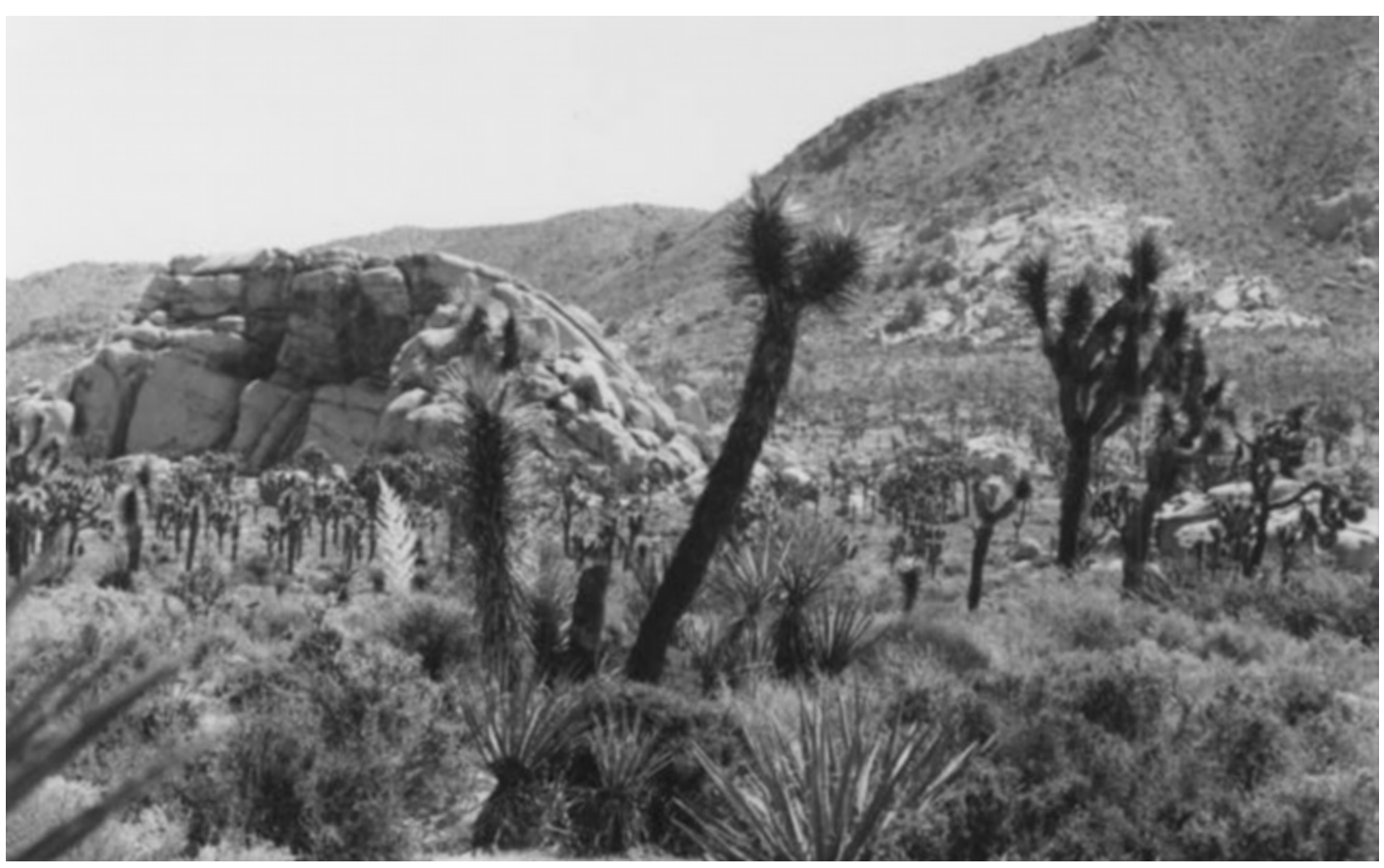

Joshua Tree National Monument - California 